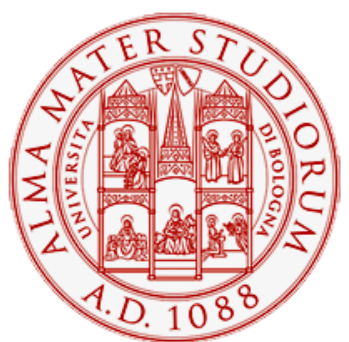

Alma Mater Studiorum - Università di Bologna DEPARTMENT OF ECONOMICS

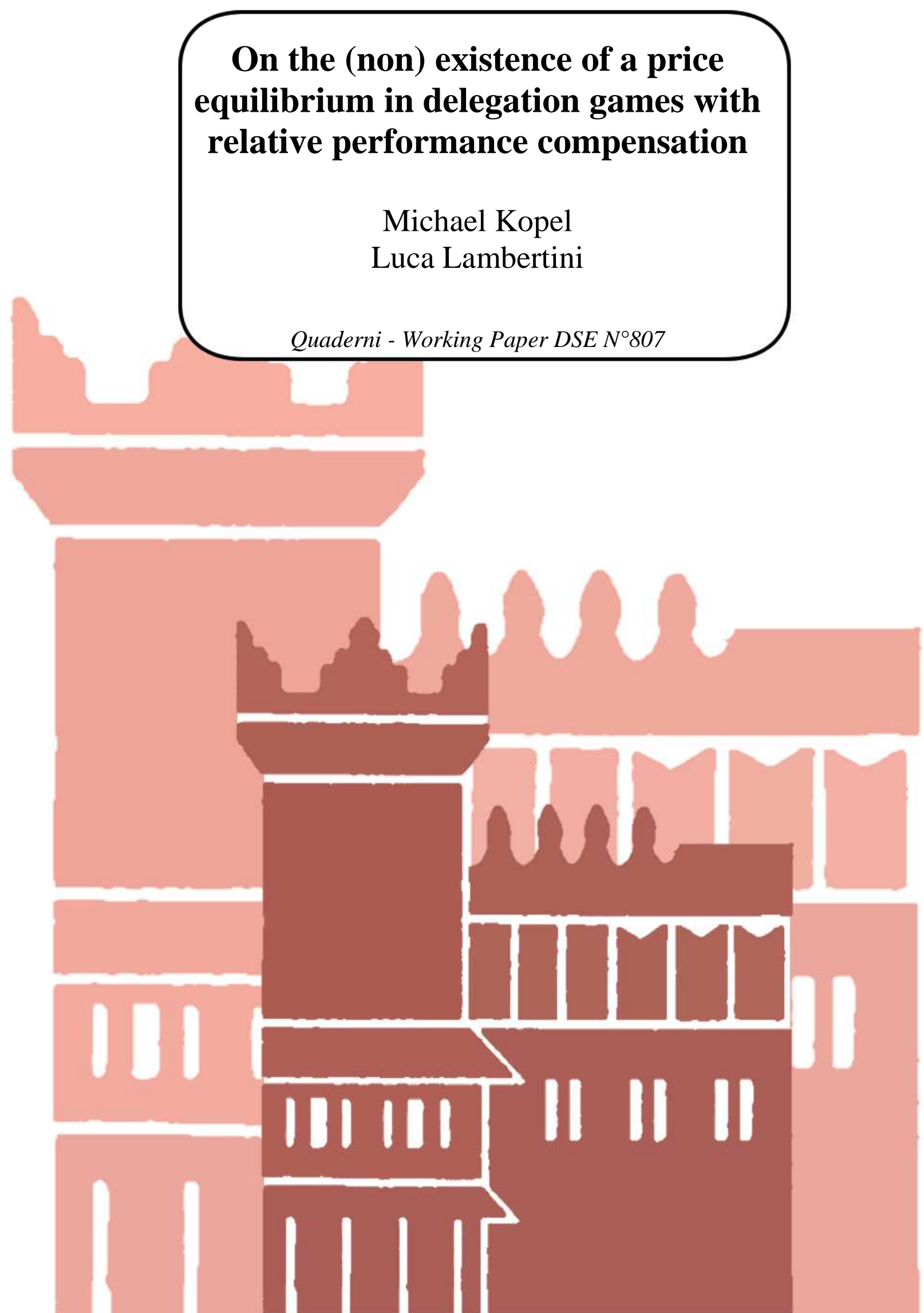




\title{
On the (non) existence of a price equilibrium in delegation games with relative performance compensation*
}

\author{
Michael Kopel ${ }^{\S}$ and Luca Lambertini $\#$ \\ $\S$ University of Graz \\ Institute of Organization and Economics of Institutions \\ Universitätsstraße 15/E4, 8010 Graz, Austria; michael.kopel@uni-graz.at \\ \# University of Bologna, Department of Economics \\ Strada Maggiore 45, 40125 Bologna, Italy; luca.lambertini@unibo.it
}

January 16, 2012

\begin{abstract}
We show that Miller and Pazgal's (2001) model of strategic delegation, in which managerial incentives are based upon relative performance, is affected by a non-existence problem which has impact on the price equilibrium. The undercutting incentives generating this result are indeed similar to those affecting the stability of price cartels.
\end{abstract}

JEL Codes: C73, L13

Keywords: managerial firms, Bertrand competition, delegation, equilibrium existence

*We thank Giacomo Calzolari, Massimo Marinacci and the audience at RCEF 2010 (Rimini) for helpful comments and discussions. The usual disclaimer applies. 


\section{Introduction}

By now, the issue of strategic delegation in oligopoly has received a large amount of attention, with several different types of contract having been taken into account. The main alternatives investigated in the literature examine managerial incentive schemes based on a weighted average of

- profits and output (Vickers, 1985);

- profits and revenues (Fershtman and Judd, 1985; Sklivas, 1987);

- Comparative performance evaluation (Miller and Pazgal, 2001);

- profits and market share (Jansen et al., 2007; Ritz, 2008).

Here we revisit the contribution by Miller and Pazgal (2001, henceforth MP), who adopt a model of strategic delegation where managerial incentives rely upon relative performance. In this case, the delegation contract establishes that a manager's objective consists in maximising a weighted average of his own firm's profits and the rival's profits w.r.t. the relevant market variable, either quantity or price. ${ }^{1}$

They claim that in such a setup, and unlike the previous approaches to strategic delegation (cf. Vickers, 1985; and Fershtman and Judd, 1987, inter alia) an equivalence result holds. That is, if the managerial objective is constructed on a relative profit performance scheme, the choice between price and quantity becomes immaterial as the equilibrium outcome is the same regardless of the way competition takes place at the market stage.

\footnotetext{
${ }^{1}$ The adoption of such objective function in a setup describing the interplay between managerial firms can be thought of as a specific instance of a general class of problems in which the relative standing of peers'outcomes influences each agent's individual preference structure (see Maccheroni, Marinacci and Rustichini, 2011).
} 
We re-examine MP's analysis to single out a mistake in the derivation of the (alleged) subgame perfect equilibrium in the model where the market stage is played in the price space. In particular, MP have overlooked a problem with price competition with perfect substitutes that requires taking limits instead of solving FOCs. When taking this into account, there appears that price competition with comparative performance evaluation contracts amounts to building up an explicit cartel that (i) should be prosecuted according to antitrust laws; (ii) is unstable, as it is subject to unilateral deviations, and therefore (iii) is not an equilibrium outcome of the two-stage delegation game.

Our analysis is also motivated by an earlier paper on relative profit incentives; see Lundgren (1996). The author argues that motivating managers to maximize relative profits rather than absolute profits will prevent collusion among the managers of different firms. He states that "The key to understanding this method rests upon ... the observation that successful collusion increases absolute profits of firms, but does not increase the relative profits of firms." (p. 534). Accordingly, firms with relative profit motives have incentive to cheat or undercut the rival's price. ${ }^{2}$

The cornerstone of our argument is the presence of an undercutting incentive that destroys the alleged candidate equilibrium for any degree of substitutability between goods. If substitutability is sufficiently high, price undercutting makes the deviating firm a monopolist, very much like what happens in the Hotelling (1929) spatial competition model with linear disutility of transportation, where each firm has an incentive to undercut the rival's price for sufficiently high degrees of substitutability between products, thereby undermining the existence of a Bertrand-Nash equilibrium in pure strategies due to insufficient product differentiation (cf. d'Aspremont et al.,

\footnotetext{
${ }^{2}$ For this method Lundgren was even granted a patent (Patent No. US 7,065,495 B1) on June 20, 2006.
} 
1979). The presence of the undercutting incentive under price competition and relative performance compensation can be also explained with reference to another stream of literature that, at first sight, might seem unrelated to the issue of strategic delegation, which is the branch of the IO literature discussing the stability of implicit collusion with differentiated products. The reason is that the adoption of delegation incentives based on relative profit performance mimics to some extent the behaviour of a cartel, as in both cases each firm internalises the effect of its own behaviour on the other firm's profits. From several contributions (cf. Deneckere, 1983; Ross, 1992; and Lambertini, 1997, inter alia), we know that if products are sufficiently similar, the unilateral deviation from implicit collusion in prices makes the cheating firm a monopolist. The intuition behind the non-existence of the price equilibrium ultimately boils down to the idea that comparative performance evaluation boosts the aggressiveness of managers and lures the owners into exploiting such aggressiveness to steal the rival's customers (eventually all of them if product differentiation is not large enough), in a destructive way.

Another way of looking at the same setup is to think of the same objective function as that of the owners, not the managers, in the case where the owner of firm $i$ buys a share of firm $j$ (and conversely), in such a way that each owner is entitled to enjoy part of the profits generated by the other firm. ${ }^{3}$ With this in mind, it is immediate to conclude that the choice between price and quantity becomes immaterial, as the two firms behave as a monopolist or a cartel, obviously indifferent between price- and quantity-setting. However, again the cartel is subject to unilateral deviations. Therefore, none of the alleged equilibria outlined by MP is indeed an equilibrium, as the delegation

\footnotetext{
${ }^{3}$ A long-standing discussion on this point exists in the literature. See, e.g., Bishop (1960), Friedman (1968), Cyert and DeGroot (1973), Bresnahan and Salop (1986), Reynolds and Snapp (1986), Clayton and Jorgensen (2005) and Kopel and Szidarovszky (2006).
} 
contract designed by Miller and Pazgal (2001) is not robust to unilateral renegotiation between owner and manager of the same firm (equivalently, in the jargon of dynamic games, any contract shaped as in MP is doomed to be time inconsistent). Moreover, this class of contracts could then appear as a way of getting around regulatory measures designed to limit horizontal mergers, by setting up cartels hidden behind the screen of a seemingly non cooperative behaviour on the part of managers in the market phase. And yet, when considered for what they really are - an instrument to build up some degree of collusion - these delegation contracts should in fact receive the closest possible attention by antitrust agencies and be prosecuted. Additionally, in an application of their model to intraindustry trade, Miller and Pazgal (2005) claim that optimal trade policy becomes insensitive to the mode of market competition if firms adopt delegation contracts based on relative performance. On the basis of our analysis, this cannot hold in equilibrium.

The remainder of the paper is structured as follows. Section 2 outlines MP's analysis and conclusions. The proof of the non-existence of equilibrium is then carried out in section 3. Concluding remarks are in section 4 .

\section{Preliminaries: Miller-Pazgal's linear model}

The main focus of Miller and Pazgal's (2001) analysis is on a model of differentiated duopoly due to Bowley (1924) and then revived by Spence (1976), Dixit (1979) and Singh and Vives (1984).

The utility function of the representative consumer, characterised by a 
preference for variety, is (cf. Singh and Vives, 1984, p. 547): ${ }^{4}$

$$
U=\alpha q_{1}+\alpha q_{2}-\frac{1}{2}\left[\beta\left({q_{2}}^{2}+q_{2}^{2}\right)+2 \gamma q_{1} q_{2}\right]
$$

where parameter $\gamma \in[-\beta, \beta]$ measures the degree of substitutability (in the positive range) or complementarity (in the negative range) between goods. If instead $\beta=0$, the two firms are independent monopolists on completely separated markets.

Inverse and direct market demand functions can be specified as follows:

$$
\begin{aligned}
p_{i} & =\alpha-\beta q_{i}-\gamma q_{j} \\
q_{i} & =\frac{\alpha}{\beta+\gamma}-\frac{\beta p_{i}}{\beta-\gamma^{2}}+\frac{\gamma p_{j}}{\beta-\gamma^{2}}
\end{aligned}
$$

depending on whether Cournot or Bertrand competition is considered, and the profit function of firm $i$ is $\pi_{i}=\left(p_{i}-c\right) q_{i}$.

The game has a standard two-stage structure, with owners playing simultaneously at the first stage in the space of delegation incentives $\left(\theta_{i}, \theta_{j}\right)$, and managers playing simultaneously either in quantities or in prices. The manager of firm $i$ maximises

$$
m_{i}=\pi_{i}+\theta_{i} \pi_{j}
$$

w.r.t. either $q_{i}$ or $p_{i}$, and receives a remuneration $\omega_{i}=A_{i}+B_{i} m_{i} \geq 0 .{ }^{5}$

\footnotetext{
${ }^{4}$ Indeed, we are using a simplified version of Miller and Pazgal's (2001) original setup, as they assume inverse demand functions:

$$
p_{i}=\alpha_{i}-\beta_{i} q_{i}-\gamma_{i} q_{j}
$$

admitting a set of asymmetric parameters. However, while assuming different $\alpha_{i}$ 's and $\beta_{i}$ 's is indeed admissible, the same does not apply for $\gamma$, as the latter parameter measures the taste for variety in the representative consumer's mind, as from (1). For more on these aspects of the model, see Singh and Vives (1984, pp. 547-48).

${ }^{5}$ Note that $A_{i}$ and $B_{i}$ need not be simultaneously positive, as long as the manager's participation constraint is satisfied. For instance, $A_{i}$ could be negative, as it would happen in the case of a franchise fee.
} 


\subsection{The MP game}

Here a brief summary of the MP game. Both firms' managers are choosing simultaneously the output or price levels. consider first the Cournot case. Proceeding by backward induction, one has to solve the Cournot-Nash game between managers and then fold the game back towards the first stage to characterise optimal incentives. For the sake of brevity, we skip the computational details and list the expressions of the equilibrium variables and objective functions (superscript $C$ standing for Cournot):

$$
\begin{gathered}
\theta^{C}=-\frac{\gamma}{2 \beta+\gamma} ; q^{C}=\frac{(\alpha-c)(2 \beta+\gamma)}{4 \beta(\beta+\gamma)} \\
p^{C}=\frac{\alpha(2 \beta-\gamma)+c(2 \beta+\gamma)}{4 \beta} \\
\pi^{C}=\frac{(\alpha-c)^{2}\left(4 \beta^{2}-\gamma^{2}\right)}{16 \beta^{2}(\beta+\gamma)} \\
m^{C}=\frac{(\alpha-c)^{2}(2 \beta-\gamma)}{8 \beta(\beta+\gamma)}
\end{gathered}
$$

The Bertrand equilibrium (according to MP) looks exactly the same in terms of optimal output, price and profits i.e., $q^{B}=q^{C}, p^{B}=p^{C}, \pi^{B}=\pi^{C}$, except that

$$
\theta^{B}=\frac{\gamma}{2 \beta-\gamma} \text { and } m^{B}=\frac{(\alpha-c)^{2}(2 \beta+\gamma)}{8 \beta(\beta+\gamma)}
$$

with $m^{B}>m^{C} \forall \gamma \in(0, \beta]$ and conversely in the negative range. In the remainder, for simplicity and without further loss of generality, we focus on the case where $\beta=1$.

At this point, three observations can be put forward:

1) Observe that, for all $\gamma \in[0,1]$,

$$
\frac{\partial \theta^{C}}{\partial \gamma}=-\frac{2}{(2+\gamma)^{2}}<0 ; \frac{\partial \theta^{B}}{\partial \gamma}=\frac{2}{(2-\gamma)^{2}}>0
$$


with

$$
\theta^{C} \in\left[-\frac{1}{3}, 0\right] ; \theta^{B} \in[0,1]
$$

so that, while $\theta^{C}$ indeed allows for an interpretation of the setup in terms of comparative performance, the functional form of $\theta^{B}$ indeed drives in the opposite direction, as delegation under Bertrand competition takes the form of an increasing degree of collusion as products become less differentiated.

2) Now, taking for granted that $\theta^{C}$ and $\theta^{B}$ are correct, one should see monopoly pricing under Bertrand competition, in correspondence of $\gamma=1$ given that $\theta^{B}=1$ with homogeneous goods, entailing that firms are fully colluding. However, from (5) we have

$$
\left.p^{B}\right|_{\gamma=1}=\left.p^{C}\right|_{\gamma=1}=\frac{\alpha+3 c}{4}
$$

which is lower than monopoly price $p_{M}=(\alpha+c) / 2$ for all $\alpha>c$.

3) Conversely, under Bertrand behaviour one would expect to observe marginal cost pricing in correspondence of $\gamma=1$ since firms set prices - at least in principle, in a fully non cooperative way - with homogeneous products. While in VFJS price competition with perfect substitutes collapses onto marginal cost pricing, here, seemingly, it doesn't.

\section{$3 \quad$ First order conditions and limit properties}

To understand the mechanics of the model, one has to delve into the details of the managers' behaviour in the price stage. The relevant first order condition at the market stage of the Bertrand game is:

$$
\frac{\partial m_{i}}{\partial p_{i}}=\frac{\alpha(1-\gamma)-\left(2 p_{i}-c\right)+\gamma\left[\theta_{i}\left(p_{j}-c\right)+p_{j}\right]}{1-\gamma^{2}}=0
$$


yielding

$$
\bar{p}_{i}=\frac{\alpha(1-\gamma)\left[2+\gamma\left(1+\theta_{i}\right)\right]-c\left[\theta_{j}\left(1+\theta_{i}\right) \gamma^{2}-\left(\gamma\left(1-\theta_{i}\right)+2\right)\right]}{4-\left(1+\theta_{i}\right)\left(1+\theta_{j}\right) \gamma^{2}} .
$$

Plugging the price pair (11) into firm $i$ 's profit function, the latter becomes:

$$
\pi_{i}=\frac{(\alpha-c)^{2}(1-\gamma)\left[2+\gamma\left(1+\theta_{i}\right)\right]\left[2+\gamma\left(1-\theta_{i}\right)-\theta_{i}\left(1+\theta_{j}\right) \gamma^{2}\right]}{(1+\gamma)\left[4-\left(1+\theta_{i}\right)\left(1+\theta_{j}\right) \gamma^{2}\right]^{2}}
$$

while output is

$$
q_{i}=\frac{(\alpha-c)(1-\gamma)\left[2-\gamma\left(\theta_{i}\left(1+\theta_{j}\right) \gamma+\theta_{i}-1\right)\right]}{(1+\gamma)\left[4-\left(1+\theta_{i}\right)\left(1+\theta_{j}\right) \gamma^{2}\right]}
$$

According to MP, $\pi_{i}$ must be maximised w.r.t. $\theta_{i}$, yielding $\theta_{i}=\theta_{j}=\theta^{B}=$ $\gamma /(2-\gamma)$. The resulting quantity, price, profits and managerial objective function should be as in (5).

This is where we start illustrating our objections to MP's claims. Our observations can be succinctly listed as follows:

Remark 1: Take $\theta_{j}=\theta_{i}=\theta$ (not necessarily MP's $\theta^{B}$, but any symmetric $\theta$ ). From (12), note that $\pi_{i}=0$ for $\gamma=1$. Therefore, one should expect marginal cost pricing to arise if firms supply perfect substitutes. However, assuming $\theta_{i}=\theta_{j}$ yields

$$
\pi_{i}=\frac{(\alpha-c)^{2}(1-\gamma)(1-\gamma \theta)}{(1+\gamma)[2-\gamma-\gamma \theta]^{2}}
$$

which takes the indeterminate $0 / 0$ form taking into account that $\theta^{B} \rightarrow$ 1 as $\gamma \rightarrow 1$. Applying the rule of de l'Hospital twice shows that the profit expression converges towards monopoly profit $\pi_{M}=(a-c)^{2} / 8$. 
Remark 2: Again, set $\theta_{j}=\theta_{i}=\theta$, to simplify (11) as follows:

$$
\left.\bar{p}_{i}\right|_{\theta_{i}=\theta_{j}=\theta}=\frac{\alpha(1-\gamma)+c(1-\gamma \theta)}{2-\gamma(1+\theta)} .
$$

Now note that assuming $\theta$ fixed implies that $p=c$ if $\gamma=1$. On the other hand, taking into account that $\theta^{B} \rightarrow 1$ as $\gamma \rightarrow 1$, then expression (15) becomes indeterminate (taking a 0/0 form). Applying de l'Hospital rule yields

$$
\left.\lim _{\gamma \rightarrow 1} \bar{p}_{i}\right|_{\theta_{i}=\theta_{j}=\theta}=\frac{\alpha+c \theta}{1+\theta}
$$

and hence convergence towards the monopoly price $p_{M}=(\alpha+c) / 2$ at $\theta=1$.

Remark 3: Alternatively, for any pair of $\theta_{i}$ and $\theta_{j}$, we have

$$
\lim _{\gamma \rightarrow 1} \bar{p}_{i}=c
$$

This reveals the problematic nature of Bertrand behaviour in the MP setup with homogeneous goods: in the neighbourhood of $\gamma=1$, the limit behaviour of the Bertrand setup is sensitive to the order according to which one evaluates the limits of the endogenous variables. The ultimate implication seems to be that symmetric incentive schemes point towards monopoly pricing, but the latter is unstable and ultimately collapses to the Bertrand paradox. This raises the issue of undercutting incentives, to which we will come back extensively in the remainder.

Remark 4: Examine the FOC on (12) as in MP:

$$
\frac{\partial \pi_{i}}{\partial \theta_{i}}=\frac{(\alpha-c)^{2}(1-\gamma)\left[2+\gamma\left(1+\theta_{j}\right)\right] \gamma^{2}}{(1+\gamma)\left[4-\left(1+\theta_{i}\right)\left(1+\theta_{j}\right) \gamma^{2}\right]^{3}} \Psi=0
$$


with

$$
\Psi \equiv\left(1+\theta_{j}\right)(2+\gamma) \gamma-\theta_{i}\left[4+\gamma\left(1+\theta_{j}\right)(2-\gamma)\right]
$$

Now set $\theta_{j}=\theta_{i}$ and rewrite the FOC as follows

$$
\frac{\partial \pi_{i}}{\partial \theta_{i}}=\frac{(\alpha-c)^{2}(1-\gamma) \gamma^{2}[\gamma-\theta(2-\gamma)]}{(1+\gamma)[2-\gamma(1+\theta)]^{3}[2+\gamma(1+\theta)]}=0
$$

and observe that the MP candidate solution, $\theta^{B}=\gamma /(2-\gamma)$ comes from $\gamma-\theta(2-\gamma)=0$. However, with $\theta=\theta^{B}$, the expression on the r.h.s. of the above FOC is indeterminate in correspondence of $\gamma=1$, since also the denominator is nil. The same applies to quantities, prices and profits because of the presence of the expression

$$
4-\left(1+\theta_{i}\right)\left(1+\theta_{j}\right) \gamma^{2}
$$

at the denominator, in all of them.

Accordingly, one has to impose $\theta_{j}=\theta_{i}$ and then resort to the limit for $\gamma \rightarrow 1$ in order to obtain the monopoly price, which, in turn, is obviously subject to undercutting. Therefore, we may state:

Proposition 1 With perfect substitutes, Bertrand competition cannot sustain equilibrium prices above marginal cost. As a result, the outcomes yielded by delegation contracts based on comparative performance evaluation are not observationally equivalent irrespective of the market variables being set by managers.

Without further discussion, it is worth noting that the same trivially holds in the mixed case in which a single firm is a price-setter while the other is a quantity setter, where marginal cost pricing emerges in correspondence of full substitutability with pure profit-seeking (entrepreneurial) firms (see Singh and Vives, 1984). 


\subsection{Product differentiation and undercutting incentives}

The next question is whether the same conclusion applies also when there exists some degree of differentiation. In this respect, our analysis replicates quite closely that of (i) d'Aspremont et al. (1979) concerning the original version of the Hotelling game, as well as (ii) Deneckere (1983), Ross (1992) and many others, concerning deviations from cartel prices in supergames based on the Singh and Vives (1984) framework.

The question we are about to address can be formulated in two alternative ways:

(i) for $\gamma \in(0,1]$, and given

$$
p_{j}=p^{B}(\theta) ; \theta_{i}=\theta_{j}=\theta,
$$

so that (11) rewrites as

$$
p^{B}(\theta)=\frac{\alpha(1-\gamma)-c(\gamma \theta-1)}{2-\gamma(1+\theta)},
$$

is there an undercutting price $p_{i}^{u}(\theta)$ that the manager of firm $i$ can choose, so as to yield $\omega_{i}^{u}=A_{i}+B_{i} m^{u}>\omega^{B}=A_{i}+B_{i} m^{B}$ and $\pi_{i}^{u}(\theta)>$ $\pi^{B}(\theta)$ ? Alternatively,

(ii) for $\gamma \in(0,1]$, can the owner of firm $i$ design an 'undercutting contract' $\theta_{i}^{u}$ such that, given

$$
p_{i}=\bar{p}_{i}\left(\theta_{i}, \theta^{B}\right) ; p_{j}=p^{B} ; \theta_{j}=\theta^{B}=\frac{\gamma}{2-\gamma}
$$

the manager of firm $i$ sets $\bar{p}_{i}\left(\theta_{i}^{u}\right)$ reproducing the same price as if the manager himself where deviating at the second stage to maximise $\pi_{i}$ ?

Route (i) Trivially, as we already know from the foregoing discussion, the answer to version (i) turns out to be positive if $\gamma=1$, where unilateral deviation involves the cheating firm setting the undercutting price

$$
p_{i}^{u}=\frac{\alpha+c}{2}-\varepsilon
$$


to obtain full monopoly profits $\pi^{M}$, as the cheated firm's sales are driven to zero. If so, then $m_{i}=\pi^{M}$ and $\omega_{i}^{u}=A_{i}+B_{i} \pi^{M}>\omega^{B}$, while ${ }^{6}$

$$
\pi_{i}^{u}=\pi^{M}-\omega_{i}^{u}=\left(1-B_{i}\right) \pi^{M}-A_{i}>\left(1-2 B_{i}\right) \frac{\pi^{M}}{2}-A_{i}
$$

reduces to

$$
1-B_{i}>\frac{1-2 B_{i}}{2}
$$

which is satisfied by any admissible value of $B_{i}$.

If instead $\gamma \in(0,1)$, we have what follows. Suppose firm $i$ undercuts firm $j$, choosing $p_{i}^{D}$ to solve

$$
\begin{aligned}
q_{j} & =\frac{\alpha}{1+\gamma}-\frac{p^{B}(\theta)}{1-\gamma^{2}}+\frac{\gamma p_{i}^{u}}{1-\gamma^{2}}=0 \Rightarrow \\
p_{i}^{u}(\theta) & =\frac{\alpha(1-\gamma)[1-\gamma(1+\theta)]+c(\gamma \theta-1)}{\gamma[\gamma(1+\theta)-2]}
\end{aligned}
$$

whereby the undercutting profits are

$$
\pi_{i}^{u}(\theta)=\frac{(\alpha-c)^{2}(1-\gamma)(1-\gamma \theta)[\gamma(1+\theta)-1]}{\gamma^{2}[\gamma(1+\theta)-2]^{2}} .
$$

Being $\gamma$ and $\theta$ confined to the unit interval, the above expression is positive for all

$$
\theta>\widetilde{\theta} \equiv \frac{1-\gamma}{\gamma}<1 \quad \forall \gamma \in\left(\frac{1}{2}, 1\right]
$$

with $\widetilde{\theta}<\theta^{B}$ for all $\gamma \in(2 / 3,1]$. It can be easily checked that

$$
\operatorname{sign}\left\{\pi_{i}^{u}(\theta)-\pi^{B}(\theta)\right\}=\operatorname{sign}\{\theta(1+\gamma) \gamma-1\}
$$

and consequently

$$
\pi_{i}^{u}(\theta)>\pi^{B}(\theta) \quad \forall \theta>\widehat{\theta} \equiv \frac{1}{\gamma(1+\gamma)}
$$

\footnotetext{
${ }^{6}$ The coefficient $\left(1-2 B_{i}\right)$ appearing on the r.h.s. of inequality $(26)$ is the limit of $\left[1-B_{i}\left(1+\theta^{B}\right)\right]$ as $\gamma$ tends to one.
} 
with $\widehat{\theta}<1$ for all $\gamma \in((\sqrt{5}-1) / 2,1] ; \widehat{\theta}<\theta^{B}$ for all $\gamma \in(0.81,1]$; and $\widehat{\theta}>\widetilde{\theta}$ always.

Hence, we may claim:

Lemma 2 Suppose $\theta_{i}=\theta_{j}=\theta$. Undercutting the rival's price so as to drive its market share down to zero is profitable for all

$$
\theta \in\left(\frac{1}{\gamma(1+\gamma)}, 1\right] ; \gamma \in(0.81,1]
$$

In this parameter region, $\left\{\theta^{B}, p^{B}\right\}$ does not identify a subgame perfect equilibrium in pure strategies.

The above discussion applies for all values of $\gamma$ and $\theta$ such that deviations give rise to monopoly. Suppose instead this is not the case, so that the cheated firm is not driven out of business. This happens whenever the price resulting from

$$
\frac{\partial \pi_{i}^{u}(\theta)}{\partial p_{i}}=0 \Rightarrow p_{i}^{u}(\theta)=\frac{\alpha(1-\gamma)(\gamma \theta-2)+c[\gamma(1+\gamma) \theta-2]}{2[\gamma(1+\theta)-2]}
$$

is such that the cheated firm's output is positive, i.e.,

$$
q_{j}\left(p_{i}^{u}(\theta)\right)=\frac{(\alpha-c)[2-\gamma(2+\gamma) \theta]}{2(1+\gamma)[2-\gamma(1+\theta)]}>0
$$

which, again considering that $\gamma$ and $\theta$ are confined in the unit interval, holds for all $\theta<\underline{\theta} \equiv 2 /[\gamma(2+\gamma)]$, with

$$
\begin{array}{ll}
\underline{\theta}<1 & \forall \gamma \in(\sqrt{3}-1,1] \\
\underline{\theta} \geq \theta^{B} & \forall \gamma \in(0,0.881,1]
\end{array}
$$

and conversely outside this region. The resulting deviation profits are:

$$
\pi_{i}^{u}(\theta)=\frac{(\alpha-c)^{2}(1-\gamma)(2-\gamma \theta)^{2}}{4(1+\gamma)[2-\gamma(1+\theta)]^{2}}
$$


with

$$
\pi_{i}^{u}(\theta)-\pi^{B}(\theta)=\frac{(\alpha-c)^{4}(1-\gamma)^{2}(2-\gamma \theta)^{2}(1-\gamma \theta)}{4(1+\gamma)^{2}[2-\gamma(1+\theta)]^{4}}
$$

which is always positive in the admissible parameter range. Accordingly, we have:

Lemma 3 Suppose $\theta_{i}=\theta_{j}=\theta$ and consider the case where undercutting the rival's price does not grant monopoly power to the deviator. In such a range, price undercutting is always profitable.

Given that there exists a managerial remuneration scheme in correspondence of which a unilateral price deviation is desirable from the owner's and the manager's standpoint alike, in correspondence of a continuum of values of $\theta$. Consequently, Lemmata 2-3 imply:

Proposition 4 Due to the presence of an undercutting incentive at the price stage, the subgame perfect equilibrium in pure strategies fails to exists for symmetric delegation contracts $\theta_{i}=\theta_{j}=\theta$.

Route (ii) Firm $j$ is playing $\left\{\theta^{B}=\gamma /(2-\gamma), p^{B}=[\alpha(2-\gamma)+c(2+\gamma)] / 4\right\}$. Given these strategies, we investigate whether, for a generic $\theta_{i}$ there exists any price interval for $p_{i}$ such that $\pi_{i}>\pi^{B}=\pi^{C}$. The expression for $\pi_{i}$ is:

$$
\pi_{i}=\frac{\left(p_{i}-c\right)\left[\alpha(4-\gamma(2+\gamma))+c(2+\gamma) \gamma-4 p_{i}\right]}{4\left(1-\gamma^{2}\right)}
$$

whereby $\pi_{i}>\pi^{B}$ for all

$$
p_{i} \in\left(\frac{\alpha[2-\gamma(1+\gamma)]+c[2+\gamma(1+\gamma)]}{4}, \frac{\alpha(2-\gamma)+c(2+\gamma)}{4}\right)
$$


the upper bound of such interval coinciding with $p^{B}$. The second step consists in taking the first order condition $\partial \pi_{i} / \partial p_{i}=0$ on (38), which is satisfied by

$$
p_{i}^{u}=\frac{\alpha[4-\gamma(2+\gamma)]+c[4+\gamma(2+\gamma)]}{8}
$$

It is then easy to verify that $p_{i}^{u}$ is the midpoint of the interval appearing in (39). The corresponding undercutting profits amount to:

$$
\pi_{i}^{u}=\frac{(\alpha-c)^{2}[4-\gamma(2+\gamma)]^{2}}{64\left(1-\gamma^{2}\right)}>\pi^{B} \forall \gamma \in(-1,1),
$$

which immediately implies that undercutting is always profitable, even in the complementarity range.

Yet, with $\left\{\bar{\theta}_{j}=\theta^{B}, p_{i}=p_{i}^{u}, p_{j}=p^{B}\right\}$ and a generic level of $\theta_{i}$, the firms' outputs are:

$$
\begin{gathered}
q_{i}=\frac{(\alpha-c)[4-\gamma(2+\gamma)]}{8\left(1-\gamma^{2}\right)} \\
q_{j}=\frac{(\alpha-c)[4-\gamma(2+\gamma(2+\gamma)]}{8\left(1-\gamma^{2}\right)}
\end{gathered}
$$

with $q_{i}>0$ for all $\gamma^{\prime}$ s, while $q_{j}>0$ for all $\gamma<\widehat{\gamma} \cong 0.881$. Hence, for all $\gamma \in(\widehat{\gamma}, 1]$, one has to solve $q_{j}=0$ to find the relevant deviation price:

$$
p_{i}^{u}\left(q_{j}=0\right)=\frac{\alpha(3 \gamma-2)+c(2+\gamma)}{4 \gamma}>c \quad \forall \gamma>\frac{2}{3},
$$

and again belonging to the interval (39). The corresponding undercutting profits are:

$$
\pi_{i}^{u}\left(q_{j}=0\right)=\left(p_{i}^{u}-c\right)\left(\alpha-p_{i}^{u}\right)=\frac{(\alpha-c)^{2}(2+\gamma)(3 \gamma-2)}{16 \gamma^{2}}
$$

Obviously, (40) and (43) coincide at $\gamma=\widehat{\gamma}$. The foregoing discussion proves:

Lemma 5 Given $\left\{\bar{\theta}_{j}=\theta^{B}, p_{i}=p_{i}^{u}, p_{j}=p^{B}\right\}$, and for any $\theta_{i}$, the price that maximises firm $i$ 's profits is

$$
p_{i}^{u}=\left\{\begin{array}{cc}
\frac{\alpha[4-\gamma(2+\gamma)]+c[4+\gamma(2+\gamma)]}{8} & \forall \gamma<\widehat{\gamma} \\
\frac{\alpha(3 \gamma-2)+c(2+\gamma)}{4 \gamma} & \forall \gamma \in(\widehat{\gamma}, 1]
\end{array}\right.
$$


with $p_{i}^{u}<p^{B}$ over the entire parameter range.

This second approach can also be interpreted in a different way. That is, we may ask ourselves whether the owner and manager of the deviating firm may indeed collude to design the optimal deviation against the rival, that is setting the candidate equilibrium contract and price. This requires finding out whether there exists a value of the delegation variable, call it $\theta_{i}^{u}$, such that, given (i) the pricing rule of firm $i$ 's managers $p_{i}=\bar{p}_{i}$ as in (11), (ii) $p_{j}=p^{B}$, and (iii) $\theta_{j}=\theta^{B}=\gamma /(2-\gamma)$, the owner of firm $i$ can induce his manager to set $p_{i}=\bar{p}_{i}\left(\theta_{i}^{u}\right)=p_{i}^{u}$ as in (40), reproducing the same situation that would be observed if the manager himself where deviating at the second stage to attain profits $\pi_{i}^{u}$. We can identify the critical level $\theta_{i}^{u}$ by using the manager's price selection given in (11) and solving:

$$
\begin{gathered}
\bar{p}_{i}\left(\theta_{i}^{u}, \theta^{B}\right)=\frac{\alpha(1-\gamma)\left[2+\gamma\left(1+\theta_{i}^{u}\right)\right]-c\left[\gamma\left(\bar{\theta}_{j}\left(1+\theta_{i}^{u}\right)+\theta_{i}^{u}-1\right)-2\right]}{4-\left(1+\theta_{i}^{u}\right)\left(1+\bar{\theta}_{j}\right) \gamma^{2}}= \\
\frac{\alpha[4-\gamma(2+\gamma)]+c[4+\gamma(2+\gamma)]}{8}
\end{gathered}
$$

to obtain

$$
\theta_{i}^{u}=\frac{\gamma^{3}}{8-\gamma[8-\gamma(2-\gamma)]}>0
$$

which holds for all $0<\gamma<\widehat{\gamma} \cong 0.881$. Within such a range of substitutability, by using $\theta_{i}^{u}$ the owner of firm $i$ can attain the undercutting profits even if his manager is using the pricing rule that solves the relevant first order condition at the second stage of the game.

To perform the same exercise in the remainder of the substitutability range, where $\gamma \in(\widehat{\gamma}, 1]$, one has to proceed as in collusion models (see Deneckere, 1983, and Lambertini, 1997, inter alia). The quantity of firm $j$, given $p_{i}=\bar{p}_{i}, p_{j}=p^{B}$, and $\theta_{j}=\theta^{B}$, becomes nil at

$$
\theta_{i}^{u}\left(q_{j}=0\right)=\frac{8(1-\gamma)+\gamma^{2}\left(2 \gamma^{2}+\gamma-4\right)}{\gamma^{2}[\gamma(3-2 \gamma)-2]}
$$


whereby firm $i$ 's manager sets $\bar{p}_{i}\left(\theta_{i}^{u}\left(q_{j}=0\right)\right)=[\alpha(3 \gamma-2)+c(2+\gamma)] /(4 \gamma)$ satisfying the first order condition and yet coinciding with (43).

The above analysis entails the following:

Lemma 6 Take $p_{i}=\bar{p}_{i}, p_{j}=p^{B}$, and $\theta_{j}=\theta^{B}$. For all levels of product substitutability, the owner of firm $i$ will find it convenient to manoeuvre the incentive scheme of his own manager so as to induce the manager to mimic a price undercutting. The related managerial incentives are:

$$
\begin{gathered}
\theta_{i}^{u}=\frac{\gamma^{3}}{8-\gamma[8-\gamma(2-\gamma)]} \forall \gamma \in(0, \widehat{\gamma}) \\
\theta_{i}^{u}=\frac{8(1-\gamma)+\gamma^{2}\left(2 \gamma^{2}+\gamma-4\right)}{\gamma^{2}[\gamma(3-2 \gamma)-2]} \forall \gamma \in(\widehat{\gamma}, 1]
\end{gathered}
$$

For $\gamma \in(\widehat{\gamma}, 1]$, firm $i$ becomes a monopolist.

Lemmata 5-6 imply our last result:

Proposition 7 For all $\gamma \in(0,1]$, the subgame perfect equilibrium of the twostage game where managerial incentives are based upon comparative profit performance fails to exist in pure strategies.

To complete the picture we now briefly comment upon managerial remuneration in the undercutting case. The associated level of $m_{i}$ is

$$
m_{i}^{u}=\frac{(\alpha-c)^{2}\{128+\gamma[\gamma(128+\gamma(32-\gamma(4-\gamma)(8+\gamma(2+\gamma))))-256]\}}{64\left(1-\gamma^{2}\right)[8-\gamma(8-\gamma(2-\gamma))]}
$$

for all $\gamma \in(0, \widehat{\gamma})$, and

$$
m_{i}^{u}\left(q_{j}=0\right)=\frac{(\alpha-c)^{2}(2+\gamma)(3 \gamma-2)}{16 \gamma^{2}}=\pi_{i}^{u}\left(q_{j}=0\right)
$$

for all $\gamma \in(\widehat{\gamma}, 1]$, as in this range firm $j$ 's profits are nil. It is easily checked that (48) and (49) are both lower than $m^{B}$. However, the manager of the 
deviating firm can be made at least as well off by manoeuvring the constants $A_{i}$ and $B_{i}$ appropriately. ${ }^{7}$

\section{Concluding remarks}

We have revisited Miller and Pazgal's (2001) model of strategic delegation with managerial contracts based upon relative performance, to single out a non-existence problem affecting the model whenever the weight attached to the rival firm's profits in the delegation contract is positive, for any degree of product differentiation. This problem is due to the fact that under Bertrand behaviour the delegation contract attaches a positive weight to the rival's profits, whereby firms closely replicate the performance of a cartel in prices, being thus subject to unilateral deviations.

We have focussed on Bertrand competition, where this issue strikingly arises, but analogous considerations apply to the mixed case where at least one firm is a price-setting agent.

\footnotetext{
${ }^{7}$ As anticipated above, an undercutting incentive also exists if one firm sets price, whereas the other firm sets quantity. We omit the analysis of this case for brevity.
} 


\section{References}

[1] Bishop, R.L. (1960), "Duopoly: Collusion or Warfare", American Economic Review, 50, 933-61.

[2] Bresnahan, T.F. and S.C. Salop (1986), "Quantifying the Competitive Effects of Production Joint Ventures", International Journal of Industrial Organization, 4, 155-75.

[3] d'Aspremont, C., J.J. Gabszewicz and J.-F. Thisse (1979), "On Hotelling's 'Stability in Competition'”, Econometrica, 47, 1045-50.

[4] Bowley, A.L. (1924), The mathematical groundwork of economics, Oxford, Oxford University Press.

[5] Clayton, M.J. and B.N. Jorgensen (2005), "Optimal Cross Holding with Externalities and Strategic Interactions", Journal of Business, 78, 150522 .

[6] Cyert, R.M. and M.H. DeGroot (1973), "An Analysis of Cooperation and Learning in a Duopoly Context", American Economic Review, 63, 24-37.

[7] Deneckere, R. (1983), "Duopoly Supergames with Product Differentiation", Economics Letters, 11, 37-42.

[8] Dixit, A. (1979), "A Model of Duopoly Suggesting the Theory of Entry Barriers", Bell Journal of Economics, 10, 20-32.

[9] Fershtman, C. and K. Judd (1987), "Equilibrium Incentives in Oligopoly", American Economic Review, 77, 927-40.

[10] Friedman, J.W. (1968), "Reaction Functions and the Theory of Duopoly", Review of Economic Studies, 35, 257-72. 
[11] Hotelling, H. (1929), "Stability in Competition", Economic Journal, 39, 41-57.

[12] Jansen, T., A. van Lier and A. van Witteloostuijn (2007), "A Note on Strategic Delegation: The Market Share Case", International Journal of Industrial Organization, 25, 531-39.

[13] Klemperer, P. and M. Meyer (1986), "Price Competition vs Quantity Competition: The Role of Uncertainty", RAND Journal of Economics, 17, 618-38.

[14] Kopel, M. and F. Szidarovszky (2006), "Resource Dynamics Under Partial Cooperation in an Oligopoly", Journal of Optimization Theory and Applications, 128, 393-410.

[15] Lambertini, L. (1997), "Prisoners' Dilemma in Duopoly (Super)games", Journal of Economic Theory, 77, 181-91.

[16] Lundgren, C. (1996), "Using Relative Profit Incentives to Prevent Collusion, Review of Industrial Organization", 11, 533-50.

[17] Maccheroni, F., M. Marinacci and A. Rustichini (2009), "Social Decision Theory: Choosing within and between Groups", Review of Economic Studies, forthcoming.

[18] Miller, N.H. and A.I. Pazgal (2001), "The Equivalence of Price and Quantity Competition with Delegation", RAND Journal of Economics, 32, 284-301.

[19] Miller, N.H. and A.I. Pazgal (2005), "Strategic Trade and Delegated Competition", Journal of International Economics, 66, 215-31. 
[20] Reynolds, R.J. and B.R. Snapp (1986), "The Competitive Effects of Partial Equity Interests and Joint Ventures", International Journal of Industrial Organization, 4, 141-53.

[21] Ritz, R.A. (2008), "Strategic Incentives for Market Share", International Journal of Industrial Organization, 26, 586-97.

[22] Ross, T. W. (1992), "Cartel Stability and Product Differentiation", International Journal of Industrial Organization, 10, 1-13.

[23] Singh, N. and X. Vives (1984), "Price and Quantity Competition in a Differentiated Duopoly", RAND Journal of Economics, 15, 546-54.

[24] Spence, M. (1976), "Product Differentiation and Welfare", American Economic Review, 66, 407-14.

[25] Vickers, J. (1985), "Delegation and the Theory of the Firm", Economic Journal, 95 (Conference Papers), 138-47. 


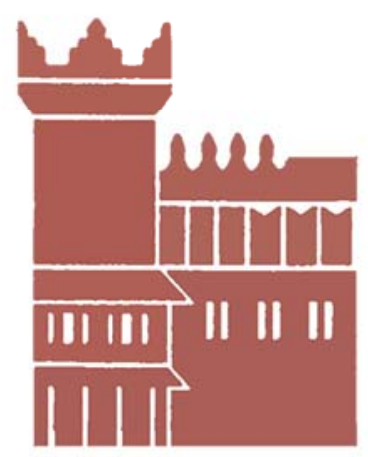

Alma Mater Studiorum - Università di Bologna DEPARTMENT OF ECONOMICS

Strada Maggiore 45

40125 Bologna - Italy

Tel. +39051 2092604

Fax +390512092664

http://www.dse.unibo.it 